\title{
ANALISIS FINANSIAL USAHA BUDIDAYA LEBAH MADU Apis cerana Fabr. DI DUSUN SIDOMUKTI DESA BUANA SAKTI KECAMATAN BATANGHARI KABUPATEN LAMPUNG TIMUR \\ (FINANCIAL ANALYSIS OF HONEY BEE (Apis cerana Fabr.) ENTERPRISES AT SUB VILLAGE SIDOMUKTI VILLAGE BUANA SAKTI SUB DISTRICT BATANGHARI EAST LAMPUNG)
}

\author{
Nanda Kurnia Sari, Rommy Qurniati, dan Rudi Hilmanto \\ Jurusan Kehutanan Fakultas Pertanian Universitas Lampung \\ Alamat : Jl. Pof. Dr. Sumantri Brojonegoro No. 1 Bandar Lampung 35145 \\ E-mail : nandakurniasari@yahoo.com
}

\begin{abstract}
ABSTRAK
Konsumsi madu di Indonesia $10 \mathrm{gr} / \mathrm{kapita} / \mathrm{tahun}$, namun produksi madu hanya memenuhi 3 gr/kapita/tahun (Murtidjo, 2011). Karena tingginya permintaan terhadap madu maka pengembangan usaha budidaya lebah madu perlu dilakukan. Penelitian ini bertujuan untuk mengetahui kelayakan finansial dari usaha budidaya lebah madu yang dilakukan di Dusun Sidomukti Desa Buana Sakti Kecamatan Batanghari Kabupaten Lampung Timur. Penelitian dilakanakan pada bulan Maret -- April 2012 menggunakan metode wawancara dengan kuisioner dan observasi langsung. Perhitungan dianalisis berdasarkan analisis R/C Ratio dan Break Event Point. Hasil penelitian menunjukkan bahwa usaha budidaya lebah madu menggunakan stup dan glodok. Berdasarkan umur ekonomis stup dan glodok selama dua tahun maka secara finansial usaha budidaya lebah madu layak dilakukan menggunakan stup dengan nilai R/C Ratio > 1 yaitu Rp 1,616 dengan jumlah yang harus diproduksi agar berada pada titik impas sebanyak 75 stup atau Rp 174.807,94/stup sehingga petani lebah memperoleh keuntungan dari usaha budidaya lebah madu Apis cerana Fabr. yang dilakukan.
\end{abstract}

Kata kunci : analisis finansial, Apis cerana Fabr., lebah madu

\begin{abstract}
Honey consumption in Indonesia 10 gr/capital/year, nevertheleses the honey production only $3 \mathrm{gr} / \mathrm{capital}$ year (Murtidjo, 2011). Due to the highest demand of honey so it is needed honey bee entrerprises. The purpose of this research was to know on financial feasibility of the Apis cerana Fabr. honey bee enterprises. The research was conducted at Sub Village Sidomukti Village Buana Sakti Sub District Batanghari East Lampung on March -- April 2012 used method interview with questionnaires and observation directly used $R / C$ Ratio and BEP (Break Event Point). The results showed that the Apis Cerana Fabr. honey bee enterprises in Sub Village Sidomukti using stup and glodok (traditional stup). Based on economic life stup and glodok for two years so financially viable honey bee enterprises performed using stup media with the value of $R / C$ ratio $>1$ is 1,616 with number to be produced to reach the break event point were 75 stup or at price Rp Rp 174.807,94/stup so the honey bee farmers will get benefit of Apis cerana Fabr. honey bee enterprises.
\end{abstract}

Key words : Apis cerana Fabr., financial analysis, honeybee 


\section{PENDAHULUAN}

Budidaya lebah madu sudah dikenal oleh masyarakat pedesaan ataupun masyarakat sekitar hutan. Hal ini dibuktikan dari tulisan Dr. D. Horst bangsa Belanda pada tahun 1861 yang menceritakan cara-cara pengambilan madu dari sarang lebah hutan, pada tahun 1864 juga ada tulisan tentang cara beternak lebah madu di Lampung, sedangkan Hoekman pada tahun 1929 menuliskan tentang peternakan lebah madu di Indonesia (Warisno, 2011).

Usaha budidaya lebah madu merupakan usaha pengembangan dan penjualan produk hasil budidaya lebah madu. Usaha tersebut dilakukan untuk memenuhi kebutuhan produk madu yang terus meningkat. Besarnya permintaan terhadap madu belum dapat diimbangi oleh kemampuan industri perlebahan dalam meningkatkan produksi madu, sehingga untuk mengatasi kondisi tersebut maka pengembangan usaha lebah madu perlu dilakukan (Adalina, 2008). Pengembangan usaha budidaya lebah madu dilakukan oleh masyarakat di Dusun Sidomukti Desa Buana Sakti Kecamatan Batanghari Kabupaten Lampung Timur sejak tahun 2006 sampai sekarang. Masyarakat di Dusun Sidomukti menjadikan hasil perkebunan dan pertanian sebagai sumber pendapatan utama, kemudian masyarakat mengkombinasikannya dengan usaha budidaya lebah madu sebagai usaha sampingan.

Kurangnya pengetahuan dan keyakinan masyarakat mengenai potensi pengembangan usaha budidaya lebah madu yang dilakukan menyebabkan usaha tersebut belum berkembang secara optimal. Oleh karena itu, perlu dilakukannya analisis finansial terhadap usaha budidaya Lebah Madu Apis cerana Fabr. yang dilakukan Kelompok Karya Tani Sejahtera di Dusun Sidomukti Desa Buana Sakti Kecamatan Batanghari Kabupaten Lampung Timur untuk mengetahui apakah usaha budidaya lebah madu secara finansial layak atau tidak layak untuk dikembangkan.

\section{METODE PENELITIAN}

Penelitian ini telah dilaksanakan di Dusun Sidomukti Desa Buana Sakti Kecamatan Batanghari Kabupaten Lampung Timur pada bulan Maret sampai April 2012 dengan objek dalam penelitian ini adalah masyarakat yang terdiri dari anggota Kelompok Karya Tani Sejahtera yang membudidayakan lebah madu. Data yang diperlukan dalam penelitian berupa data umum rumah tangga, potensi ekonomi, biaya variabel (biaya operasional), dan biaya tetap (biaya investasi) yang diambil menggunakan metode wawancara dan observasi. Penentuan responden petani lebah madu sebanyak 23 responden yang dilakukan dengan menggunakan metode sensus penduduk. Sensus penduduk merupakan teknik penentuan responden yang dipilih karena jumlah populasi kurang dari 100 orang (Arikunto, 2002).

Perhitungan dianalisis kelayakan berdasarkan analisis R/C Ratio yaitu perbandingan antara total penerimaan dengan total biaya dan Break Event Point (BEP) yaitu untuk mengetahui titik pulang pokok dimana total revenue sama dengan total cost. Sehingga dapat diketahui bahwa usaha budidaya lebah madu Apis cerana Fabr. layak atau tidak untuk dilakukan.

\section{HASIL DAN PEMBAHASAN}

Usaha budidaya lebah madu di Dusun Sidomukti menggunakan stup dan glodok sebagai sarang buatan untuk lebah madu. Glodok yang digunakan terbuat dari batang pohon kelapa atau randu yang pucuknya dibelah dengan panjang 50-60 cm. Isi di bagian tengahnya diambil sebagian supaya bila belahan batang pohon kelapa dijadikan satu akan terlihat berongga. Biasanya petani lebah membeli dengan harga Rp 25.000,-/glodok. Stup terbuat dari kayu akasia berbentuk seperti peti persegi dengan ukuran tutup $45 \mathrm{~cm}$ x $35 \mathrm{~cm}$ x $30 \mathrm{~cm}$ 
dan ukuran kotaknya $40 \mathrm{~cm}$ x $30 \mathrm{~cm}$ x $25 \mathrm{~cm}$ yang dicat putih dan didalamnya terdapat sisiran berjumlah 6-7 sisiran. Menurut Warisno (2011) stup yang terbaik saat ini berupa bangunan berbentuk peti dengan isi 6-12 sisiran. Sehingga stup yang digunakan sudah tergolong baik. Petani lebah biasanya membeli dengan harga Rp 100.000,-/stup.

Pemasangan stup dan glodok diletakkan di bawah pohon atau di sekitar kandang ternak dan pekarangan rumah dengan jenis pakan lebah yang terbatas yaitu jenis akasia (Accacia mangium) dan cokelat (Theobroma cacao). Sedangkan lokasi yang memenuhi persyaratan untuk memelihara lebah madu adalah daerah-daerah yang memiliki tanaman berbunga yang disukai lebah madu dan tersedia sepanjang tahun (Murtidjo, 2011). Oleh karena itu pemasangan stup dan glodok harus disesuaikan pada lokasi dengan pakan lebah yang melimpah.

Pemeliharaan dilakukan dengan cara membersihkan stup dan glodok dari semut, kecoa, cicak, dan hewan pengganggu lainnya. Menurut Murtidjo (2011) menjaga kebersihan stup sangat penting agar kenyamanan koloni lebah tidak terganggu. Tetapi petani lebah di Dusun Sidomukti hanya sebagian saja yang melakukan pemeliharaan. Sehingga banyak lebah yang pergi dari stup dan glodok untuk mencari sarang yang lebi nyaman.

Pembibitan lebah madu dilakukan petani lebah di Dusun Sidomukti dengan cara berburu koloni. Petani lebah belum memiliki pengetahuan untuk melakukan perkembangbiakan lebah ratu sehingga petani lebah melakukan perburuan langsung di sekitar aliran sungai. Berburu tidak dilakukan oleh seluruh petani lebah karena sebagian besar masih takut untuk mendekati lebah.

Hasil dari usaha budidaya lebah madu di Dusun Sidomukti adalah madu dan koloni. Produk lain seperti royal jelly, lilin lebah, propolis, dan tepung sari belum diproduksi karena kurangnya pengetahuan petani lebah untuk melakukan pemanenan. Hasil madu yang diperoleh stup yaitu $1 \mathrm{~kg}--1,5 \mathrm{~kg} / \mathrm{bulan}$ sedangkan glodok hanya menghasilkan $2--3 \mathrm{ml} / \mathrm{bulan}$. Hal ini sesuai dengan Warisno (2011) yang menyatakan bahwa pemanenan madu dengan stup hasilnya lebih banyak dibandingkan dengan glodok. Sehingga untuk memperoleh madu dalam jumlah yang banyak maka petani lebah lebih baik menggunakan stup dibanding menggunakan glodok.

Penjualan madu menggunakan botol atau plastik yang dikemas dalam satuan kilogram dengan harga $\mathrm{Rp} 60.000$,-/kg dan kadar air 25\%-27\%. Harga madu di Dusun Sidomukti merupakan ketetapan kelompok yang sudah disesuaikan dengan harga madu yang saat ini berlaku di pasaran. Sedangkan koloni dijual dengan harga Rp 50.000,-/glodok dan Rp 350.000,-/stup. Produk tersebut dijual kepada pengumpul atau konsumen yang datang langsung sehingga petani lebah tidak mengeluarkan biaya pengangkutan.

Usaha pemeliharaan lebah madu memerlukan lokasi yang kaya tanaman pakan lebah. Idealnya untuk tanaman seluas 1 ha hanya untuk satu koloni lebah dan dikelola secara tepat guna (Murtidjo, 2011). Kenyataannya di Dusun Sidomukti pada tahun 2010--2011 memproduksi 230 koloni dengan total luas lahan penangkaran dan pekarangan petani lebah kurang lebih 43 ha. Koloni tersebut terbagi atas 100 stup yang diletakkan pada lokasi penangkaran seluas 26 ha dan 51 stup terbagi pada lokasi lahan pekarangan petani lebah yang kisaran luasnya 0,5--1 ha dan diletakkan berdampingan dengan kisaran 3--10 stup. Sisanya 79 glodok diletakkan berdekatan dengan jarak antar media adalah 5--10 meter. Hal tersebut menyebabkan terjadinya ketidakseimbangan antara jumlah koloni dengan ketersediaan pakan yang ada karena tingginya tingkat persaingan lebah untuk mencari makan sehingga lebah pergi meninggalkan stup atau glodok karena pakan lebah belum mencukupi kebutuhan lebah madu untuk memproduksi madu dalam jumlah yang banyak. Jenis-jenis tumbuhan pakan lebah yang terdapat di lokasi penelitian dapat dilihat pada Tabel 1. 
Tabel 1. Jenis-jenis tumbuhan pakan lebah yang terdapat di lokasi penelitian.

\begin{tabular}{ccc}
\hline No. & Jenis Tumbuhan & Nama Ilmiah \\
\hline 1 & Akasia & Acacia auliculiformis \\
2 & Akasia Mangium & Acacia mangium \\
3 & Alang-Alang & Imperata cylindrical \\
4 & Alpukat & Persea Americana \\
5 & Babadotan & Ageratum conyzoides \\
6 & Bunga Kertas & Rhododendron indicum \\
7 & Coklat & Theobroma cacao \\
8 & Jagung & Zea mays \\
9 & Padi & Oryza sativa \\
10 & Karet & Manihot glaziovii \\
11 & Rambutan & Nephelium lappacum, $\mathrm{L}$ \\
\hline
\end{tabular}

Sumber: Analisis data primer tahun 2012

Tabel 2. Analisis total biaya dan total penerimaan dari usaha budidaya lebah madu Apis cerana Fabr. yang dilakukan Kelompok Karya Tani Sejahtera tahun 2010-2011 dalam satuan rupiah ( $\mathrm{Rp} /$ periode).

\begin{tabular}{ccccc}
\hline No. & Jenis & $\begin{array}{c}\text { Total Biaya } \\
\text { (Rp/periode) }\end{array}$ & $\begin{array}{c}\text { Total Produksi } \\
\text { (Rp/periode) }\end{array}$ & $\begin{array}{c}\text { Total Penerimaan } \\
\text { (Rp/periode) }\end{array}$ \\
\hline 1. & Stup & Rp 29.396.000,- & 151 Stup & Rp 42.660.000,- \\
2. & Glodok & Rp 4.400.000,- & 79 glodok & Rp 3.825.000,- \\
\hline
\end{tabular}

Sumber: Analisis data primer tahun 2012

Tabel 3. Hasil perhitungan analisis BEP unit dan BEP harga dari usaha budidaya lebah madu Apis cerana Fabr. yang dilakukan oleh Kelompok Karya Tani Sejahtera Tahun 2010-2011 dalam satuan rupiah (Rp).

\begin{tabular}{llll}
\hline No & Jenis barang & BEP unit $(\mathbf{R p})$ & BEP harga (Rp) \\
\hline 1. & Glodok & 60 glodok & Rp 55.696,20/glodok \\
2. & Stup & 75 stup & Rp 174.807,94/stup \\
\hline
\end{tabular}

Sumber: Analisis data primer tahun 2012

Menurut Hilmanto (2010) sumber pakan lebah madu merupakan jenis multi flora pada sistem agroforestri yaitu randu (Ceiba pentadra), karet (Havea brasiliensis), cengkeh (Eugenia aromatic), durian (Durio zybethinus), kopi (Coffea canephora), kakao (Theobrama cacao) rambutan (Nephellium lappaceum), mangga (Mangifera indica), kaliandra (Calliandra callothyrsus), jambu air (Eugenia aquaea), mahoni (Swietenia mahagony), dan tanaman pertanian. Sedangkan sistem agroforestri di Dusun Sidomukti hanya mengkombinasikan tanaman kakao dengan tanaman kehutanan akasia mangium yang ditanam untuk membangun hutan rakyat di Desa Buana Sakti. Biaya pembibitan yang dikeluarkan diluar dari total biaya produksi dalam usaha budidaya lebah madu dan pemeliharaannya juga dilakukan oleh pemilik lahan. Pemilihan bibit disesuaikan pada lokasi penanaman dengan harapan memperoleh keuntungan di masa yang akan datang.

Selama ini petani lebah hanya menanam akasia mangium dan jati saja, padahal jenis durian (Durio zibethinus), randu (Ceiba petandra), sengon (Albizia falcata), sonokeling (Dalbergia latifolia), dan waru gading (Nyssa javanica) merupakan tanaman kehutanan yang 
disukai oleh lebah. Hal ini sesuai dengan Murtidjo (2011) yang menyatakan bahwa durian dan randu merupakan salah satu jenis tanaman pakan lebah yang menghasilkan $20 \mathrm{~kg} / \mathrm{ha}$ pada musim bunga bulan September-Oktober untuk durian dan randu pada bulan April-Juni.

Kesadaran petani lebah untuk melakukan penanaman baik tanaman pakan lebah atau pun tanaman kehutanan masih rendah karena kurangnya pembinaan lanjutan terhadap petani lebah dan usaha budidaya lebah madu merupakan usaha sampingan yang dilakukan hanya untuk menambah penerimaan saat hasil pertanian dan perkebunan belum bisa diperoleh. Padahal usaha pemeliharaan lebah madu memberikan dampak positif terhadap proses kelangsungan pelestarian hutan untuk meningkatkan produktivitas tanaman hutan ataupun perkebunan karena sifatnya membantu penyerbukan bunga (pollimer) (Murtidjo, 2011).

Perhitungan analisis kelayakan finansial dari usaha budidaya lebah madu menggunakan R/C Ratio dengan membandingkan antara total penerimaan dengan total biaya yang dikeluarkan berdasarkan umur ekonomis stup atau gelodok yang digunakan yaitu dua tahun pada periode tahun 2010-2011. Dalam menganalisis ada dua jenis modal yang digunakan, yaitu modal investasi (biaya tetap) dan modal kerja (biaya variabel). Modal investasi terdiri dari stup, glodok dan peralatan kerja seperti standar kayu, sikat lebah, kurungan ratu, topi masker, kawat baja, pisau madu, skrap buah dan sarung tangan. Sedangkan modal kerja terdiri dari seluruh biaya operasional yang terdiri dari biaya tenaga kerja berburu koloni, tenaga pemeliharaan, tenaga pemanenan, tenaga pengemasan yaitu biaya untuk karet, botol dan plastik. Hasil perhitungan total biaya dan penerimaan dapat dilihat pada Tabel 2.

Total penerimaan yang dihitung dalam penelitian ini adalah semua produk stup, glodok dan madu yang terjual sedangkan total biaya adalah seluruh biaya yang dikeluarkan dalam usaha budidaya lebah madu tahun 2010-2011. Berdasarkan Tabel 2. diketahui total biaya yang dikeluarkan dalam usaha budidaya lebah madu untuk stup adalah $\mathrm{Rp}$ 29.396.000,/periode dan glodok Rp 4.400.000,-/periode dengan total penerimaan di periode yang sama untuk stup sebesar Rp 42.660.000,-/periode dan glodok Rp 3.825.000,-/periode. Walaupun biaya pembuatan stup yang dikeluarkan relatif mahal dan sulit dibandingkan dengan glodok tetapi stup dapat menghasilkan penerimaan lebih besar dibanding glodok.

Hasil perhitungan R/C Ratio untuk usaha budidaya lebah madu menggunakan glodok adalah 0,869 sehingga sesuai dengan kriteria yang digunakan, jika $\mathrm{R} / \mathrm{C}<1$ maka usaha tidak layak untuk dilakukan. Sebagian besar petani lebah memang hanya memfokuskan untuk menjual koloni lebah tanpa menjual madu karena hasil madu yang diperoleh relatif sedikit dan petani lebah masih takut untuk mendekati lebah sehingga bila glodok sudah terisi oleh koloni maka pada waktu satu sampai tiga bulan pemeliharaan kemudian dijual.

Hasil perhitungan R/C Ratio untuk usaha budidaya lebah madu yang menggunakan stup bernilai $\mathrm{Rp}$ 1,616 artinya setiap biaya $\mathrm{Rp}$ 1,- yang dikeluarkan akan menghasilkan penerimaan Rp 1,616 sehingga usaha layak dilakukan. Hasil yang diperoleh sesuai dengan hasil penelitian sejenis mengenai analisis finansial usaha budidaya lebah madu Apis cerana Fabr. di Dusun Selingkut Hulu yang layak dikembangkan karena R/C > 1 yaitu Rp 2,53 (Irza, 2007). Perbedaan nilai R/C Ratio yang diperoleh antara usaha budidaya lebah madu di Dusun Sidomukti dengan Dusun Selingkut Hulu dipengaruhi oleh jumlah pakan yang masih tersedia cukup banyak dan hasil yang diperoleh dari usaha budidaya lebah madu tidak hanya madu dan koloni, petani lebah juga sudah memproduksi lilin lebah. Berbeda dengan petani lebah di Dusun Sidomukti yang hanya memproduksi koloni dan madu dengan jumlah pakan lebah yang terbatas.

Hasil perhitungan terhadap BEP dari usaha budidaya lebah madu yang dilakukan oleh Kelompok Karya Tani Sejahtera dapat dilihat pada Tabel 3.

Berdasarkan Tabel 3 agar produksi glodok berisi koloni mencapai titik impas, maka petani lebah harus memproduksi 60 glodok dengan harga jual rata-rata sebesar Rp 55.696,20/glodok. Kenyataannya petani lebah sudah memproduksi 79 glodok selama dua 
tahun terakhir dengan harga rata-rata $\mathrm{Rp} 48.417,72$ /glodok. Hal ini menunjukkan bahwa produksi glodok sudah melewati titik impas namun harga yang ditetapkan belum mencapai titik impas sehingga perlu adanya penetapan harga yang sesuai agar petani lebah tidak mengalami kerugian.

Analisis perhitungan agar usaha budidaya lebah madu menggunakan stup mencapai titik impas, maka petani lebah harus memproduksi 75 stup dengan harga Rp 174.807,94/stup. Kenyataannya petani lebah sudah memproduksi 151 stup dengan harga jual Rp 350.000,/stup. Selain koloni, petani lebah juga menjual madu dari usaha budidaya lebah madu menggunakan stup. Selama dua tahun terakhir petani lebah sudah menjual $221 \mathrm{~kg}$ madu yang dijual dengan harga Rp $60.000 / \mathrm{kg}$. Hal ini menunjukkan bahwa produksi stup sudah melewati titik impas sehingga petani lebah memperoleh keuntungan.

Perbedaan jumlah madu yang diperoleh petani lebah di Dusun Sidomukti dipengaruhi oleh perbedaan dimensi ruang stup dan glodok yang digunakan sebagi media dalam usaha budidaya lebah madu. Sehingga walaupun jumlah pakan melimpah jika ruang untuk menyimpan madu kecil, maka madu yang diperoleh sedikit. Keberhasilan usaha budidaya lebah madu sangat dipengaruhi juga oleh ketersediaan pakan lebah. Madu dapat dipanen dalam jumlah yang besar pada lokasi yang kaya akan sumber pakan lebah dibandingkan yang hanya diletakkan di sekitar kandang ternak yang jauh dari sumber air dan ketersediaan pakan lebah yang sedikit.

Usaha budidaya lebah madu di Dusun Sidomukti sampai saat ini masih mengembangkan usaha pembibitan lebah madu saja karena lebah yang dipelihara adalah jenis lebah yang mudah kabur sehingga untuk mengurangi resiko lebah meninggalkan sarang, petani lebah langsung menjualnya. Hal tersebut yang menyebabkan petani lebah tidak memproduksi madu. Meskipun usaha budidaya lebah merupakan usaha sampingan, namun jika petani lebah mengelolanya dengan tepat guna dan mulai memproduksi produk lebah seperti madu, lilin lebah, propolis dan lainnya maka petani lebah akan memproleh keuntungan. Karena selain potensi hutan rakyatnya, Desa Buana Sakti memiliki 43 jenis tumbuhan, 37 jenis diantaranya merupakan sumber pakan lebah yang terdiri dari tanaman perkebunan, pertanian, tanaman hias, tanaman kehutanan dan rumputan (Priyono, 2012). Sehingga usaha budidaya lebah madu di Dusun Sidomukti Desa Buana Sakti akan berkembang menjadi salah satu sentra produksi madu di Propinsi Lampung.

\section{SIMPULAN}

Usaha budidaya lebah madu Apis cerana Fabr. di Dusun Sidomukti menggunakan dua jenis media yaitu glodok dan stup.

Berdasarkan umur ekonomis stup dan glodok selama dua tahun maka secara finansial usaha budidaya lebah madu layak dilakukan menggunakan stup dengan nilai R/C Ratio $>1$ yaitu 1,616 dengan jumlah yang harus diproduksi agar berada pada titik impas sebanyak 75 stup atau Rp 174.807,94/stup. Usaha budidaya lebah madu yang menggunakan glodok nilai R/C Ratio < 1 yaitu 0,869 dengan BEP unit 60 glodok atau Rp 55.696,20/glodok. Sehingga glodok kurang layak secara finansial untuk digunakan.

\section{DAFTAR PUSTAKA}

Adalina, Y. 2008. Analisis finansial usaha lebah madu Apis mellifera L. Jurnal Penelitian Hutan dan Konservasi Alam. Vol.V No.3:217-237 22 Juli 2008. Diakses pada tanggal 16 Desember 2011/22.23 wib. http://isjd.pdii.lipi.go.id/admin/jurnal/ 5308217237.pdf. 
Arikunto, S. 2002. Prosedur Penelitian Suatu Pendekatan Praktek. Buku. Aneka Cipta. Jakarta.

Hilmanto, R. 2010. Analisis paket teknologi lokal dalam pengelolaan produk madu organik untuk pasar global dan industri. Prosiding (Unila). Hal. A-74-A-82. ISBN: 978-9798510-19-9.

Irza, Y. 2007. Analisis hasil usaha lebah madu (Apis cerana) dan kontribusinya terhadap pendapatan rumah tangga kelompok tani "Madu Jaya Lestari”, Dusun Selingkut Hulu Pekon Sindang Pagar Kecamatan Sumber Jaya Kabupaten Lampung Barat. Skripsi Jurusan Kehutanan Fakultas Pertanian Universitas Lampung. Bandar Lampung. Tidak Dipublikasikan.

Murtidjo, B. A. 2011. Memelihara Lebah Madu. Buku. Kanisius. Yogyakarta. 64 hlm.

Warisno. 2011. Budidaya Lebah Madu. Buku. Kanisius. Yogyakarta. 51 hlm. 
Vol. I No. I. September 2013 (29-36)

Halaman ini sengaja dikosongkan 